\title{
Impact of Management Quality and Workforce Quality on Organizational Performance: A Case Study of Sri Lanka
}

\author{
Hewa Diddenige Upul Indrajith ${ }^{1}$, Fauzul Mafasiya Fairoz ${ }^{2, ~ * ~}$ \\ ${ }^{1}$ Access Engineering PLC, Colombo, Sri Lanka \\ ${ }^{2}$ Department of Management and Entrepreneurship, University of Ruhuna, Matara, Sri Lanka \\ Email address: \\ Indrajith33@yahoo.com(H. D. U. Indrajith), mafasiyaf@gmail.com(F. M. Fairoz) \\ ${ }^{*}$ Corresponding author
}

To cite this article:

Hewa Diddenige Upul Indrajith, Fauzul Mafasiya Fairoz. Impact of Management Quality and Workforce Quality on Organizational Performance: A Case Study of Sri Lanka. Journal of Human Resource Management. Vol. 6, No. 1, 2018, pp. 37-43. doi: $10.11648 /$ j.jhrm.20180601.15

Received: March 12, 2018; Accepted: March 30, 2018; Published: May 5, 2018

\begin{abstract}
This research aims to enhance the understanding of the relationship between management quality and workforce quality on organizational performance. Self-administered questionnaire was used to collect the data to measure the constructs of variables. The target population of this study was the management level employees at one of the foremost engineering company in Sri Lanka. A sample of 104 employees were randomly selected for interviews comprising of the all three levels of top, middle and lower levels of management and few customers were randomly selected to measure their level of satisfaction of the services offered, to illustrate the organisational performance. The study applied quantitaive method and regression analysis to analyze data. Findings show that there is a significant positive relationship between workforce quality and orgnizaional performance as well as management quality and organizational performance.
\end{abstract}

Keywords: Management Quality, Workforce Quality, Organizational Performance, Sri Lanka

\section{Introduction}

The workplace quality has gradually developed with the identification of a number of practices for effective quality management. The quality leaders believe that management and the system are the cause of poor quality rather than the workers [14]. Research literature shows that specific organizations have achieved better performance than competitors, but the causes for this outperformance are unambiguous [15]. The difference in performance could be identified with respect to local circumstances, types of products and services delivered historical developments, cultural differences, complexity of the industry, or even sheer luck [20]. In addition to this, many studies have revealed that there is a correlation between the techniques and methods organizations apply and the organizational performance they achieve. However, these studies have not revealed the direction of these correlations. This thus leaves open the issue of causality: Does applying certain management practices lead to improved performance, or do organizations with improved performance have the means to apply certain management practices? Basically the question is: what causes what? However, causality in management study is not easy to establish as there are many research problems, mainly caused by the many influences which interfere and influence the organizational performance [18]. Management quality has been a research topic for many management researchers that has occupied, investigating the effects of management practices on organizational performance [18]. Management Quality is building trust, treating fair, respect others, high commitment and action-oriented decision-making style that the management practice in any type of organization, and an important determinant of high performance organization [10]. Though there are abundant literature on management practices and organizational performance, none of the studies were focused on management quality and workforce quality to determine the organizational performance in a separate study especially in Sri Lankan context. Therefore this research aims to investigate the impact of management and workforce quality on organizational performance of one of the leading engineering company in Sri Lanka. 
The company entered into the construction sector to secure itself a niche market for providing turnkey engineering services for gabion related structures. Having optimized the available business opportunities in this sector, it gradually expanded its engineering services to cater to the demands of many aspects of the engineering industry in Sri Lanka. The company at present stands today in the forefront of the engineering sector in Sri Lanka rendering its expertise in diversified fields including civil construction, electrical engineering, infrastructure development, marine works, telecommunications etc. The company provides turnkey engineering solutions including design, procurement, and construction and commissioning of many multi-disciplinary engineering projects for customers both in the state and private sectors. As a result of the ongoing expansion, most of the management and support staff involved in project implementation are located at a purpose built projects office.
The company is recognized as a major and specialist contractor by the National Construction Association of Sri Lanka with a highest grading for all major disciplines of civil engineering. However, the company has been experienced with high labor turnover with the increasing number of employment during the previous years. Table 1 presents the financial performance and work force data which illustrates that the company has been experiencing high labor turnover during the period of 2007 to 2013.

Therefore the quality concepts at workplace are an important area to investigate and there is a need for further study into the relationship between management practices and organizational performance. Thus, based on the background and the research gap, this study addressed the following research question; "What is the level of impact on the organizational performance caused by workforce quality and management quality?"

Table 1. Financial performance and work force data.

\begin{tabular}{llllll}
\hline \multirow{2}{*}{ Item description } & Financial Years & & & \\
\cline { 2 - 6 } & $\mathbf{2 0 0 7 / 8}$ & $\mathbf{2 0 0 8} / \mathbf{9}$ & $\mathbf{2 0 0 9 / 1 0}$ & $\mathbf{2 0 1 0 / 1 1}$ & $\mathbf{2 0 1 1 / 1 2}$ \\
\hline Revenue (Million) & 2,469 & 3,385 & 3,033 & 3,518 & 6,961 \\
Profit before Tax (Million) & 397 & 960 & 961 & 1,144 & 1,732 \\
Manpower (Nos) & 1,175 & 1,556 & 1,525 & 1,628 & 3,245 \\
Labour Turnover (Nos) & 47 & 93 & 53 & 49 & 97 \\
\hline
\end{tabular}

Source: Annual Report, 2013

\section{Literature Review}

\subsection{Management Quality and Organizational Performance}

The issue of organizational performance and the management quality centers around the question: Do certain management practices cause better performance or do better performing organizations find it easier to adopt certain management practices? [4]. Many management research studies look into the relationship between organizations that practice certain management techniques and their organizational performance and they find a positive relationship between these two. However, the same research has struggled to provide evidence on the causality in these relations. Therefore, it does not state with certainty that certain management practices lead to have improved organizational performance. This could have even been the case with respect to the reciprocal causality where feedback occurs with the management practices and organizational performance that influence and interact with each other [2]. However, this relationship has not prevented consultants and management writers to claim that their techniques and frameworks, when executed properly, will increase organizational performance.

[17] investigated the direct and indirect effects of selected management practices on the financial performance of small Belgian construction companies using a structural model, and found that practices such as avoiding cash credits and a priori screening of clients had a positive effect on financial performance. [7] studied the effect of senior management initiatives on the performance of non-government organizations of the entity and found positive effects for the time span of the strategic plan, industry and government relations, and senior management ability to maneuver in the external environment with market-driven philosophy. [1] measured managers' perceptions of their effectiveness in administering twenty selected management practices and then looked at the correlation between the most effective management practice and organizational productivity, with performance management practices yielding the most significant relationship. [15] investigated the effect of 18 management practices on the performance of for-profit firms and NPOs in southeast Wisconsin and found that management practices did not have a statistically significant impact on the economic performance of for-profit firms and a strongly significant impact on not-for-profit organizations. An exception on the research into correlation between management practices and organizational performance is the ambitious work of [4]. To do this, the researchers divided a group of small to medium-sized textile plants into two categories. Both categories received an introduction into basis management practices and lean manufacturing techniques, after which one category received continuous consulting services in these areas for an extended period of time. Organizations did not receive any further support for other category and, if they wanted, had to implement these management practices themselves. After one year, the category which support had achieved a 17 percent increase in productivity, improved quality and reduced inventories and had within three years opened additional production 
facilities. The other category only achieved a limited increase. [4] concluded that the difference between the results of both category firms was down to the fact that one category had adopted the management practices while the other category had not, and thus that there was causality going from management practices to organizational performance. However, despite the commend ability of this study; some critical remarks can be made. Their study takes a specific view of management practices, i.e. mainly operational techniques and methods. But there is much more to management practices which should be taken into account, specifically more strategic, leadership and human research techniques like setting vision and strategy, coaching, and inspiring [25].

\subsection{Workforce Quality and Organizational Performance}

Workforce quality means that employees are motivated to improve their skills, and creativity to achieve better results while accountable for their performance [11]. As discussed previously, quality needs to be a product of warm, caring human relationships [12]. One of the other key factors to quality is the level of employee empowerment. Some definitions of empowerment describe it as a "psychological mindset," that comprises a number of dimensions. They are; the fit between one's job and personal values, the belief that one has the necessary knowledge and skills etc. to perform a job and the belief that one's ability to make a difference with respect to achieving organizational outcomes [8]. The basic assumption is the individual's contribution to accomplish organizational objectives and goals that could be enhanced through proper and sustained cooperation with others [8]. The outcomes of a program for improvement of quality depend heavily on the employee commitment [16]. Study discovered that in order to ensure the employees' commitment to the improvement of quality and compliance with the new policies, managers should understand the strategies that influence the compliance of workers. Then policies for quality could be formulated that are effective in improving performance.

The bottom line of any organization is known to be the profit according to many organizations in Sri Lanka. "In today's environment, creating a sustainable organization requires understanding the short-and longer-term factors that affect an organization and the market. In other words, success in today's ever-changing, globally competitive environment demands agility-a capacity for faster and more flexible responses to the needs of customers and other stakeholders" Dr. Lalith N. Senaweera, Director General, Sri Lanka Standards Institution (Daily News, April, 2013). In the Sri Lankan context some quality awards such as Sri Lanka National Quality Award (SLNQA) focuses on management quality, leadership and workforce quality in business organizations. Workforce quality examines how the organization engages, manages, and develops the company's workforce to utilize its full potential in alignment with the organization's overall mission, strategy, and action plans. The category examines the ability to assess workforce capability and capacity need and to build a workforce environment conducive to high performance. [9] evaluated the High Performance Organization (HPO) framework in the North American context, where Management quality and Workforce quality are two criteria of HPO. A longitudinal study was applied by using a questionnaire survey in 2013 and 2015. Study was conducted at seven Swagelok locations in the United States and Canada to test the ideas in practice over a period of time to evaluate their relevance to managerial practice and improvement. Results show that the application of the HPO Framework had different outcomes depending on local circumstances. Some locations experienced a growth while other locations used the framework to battle the consequences of negative economic conditions.

Based on the aforesaid argument, the following two hypotheses are formed and the research model is illustrated in Figure 1.

$\mathrm{H}$ 1: There is a positive relationship between workforce quality and organizational performance

$\mathrm{H}-2$ : There is a positive relationship between management quality and organizational performance

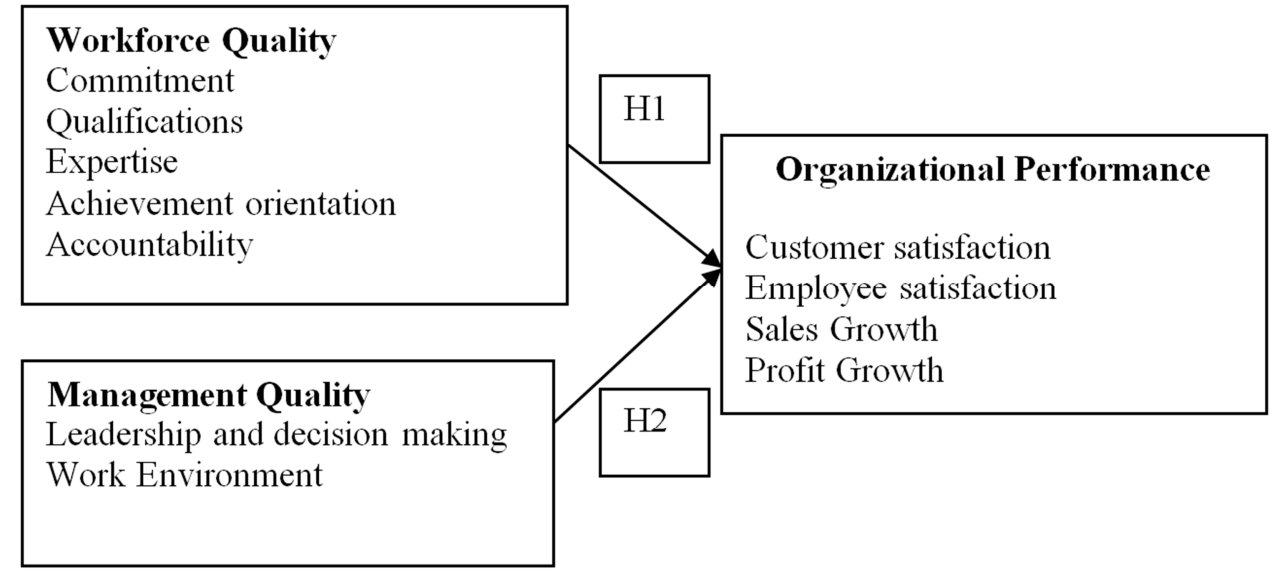

Figure 1. Research Model. 


\section{Research Method}

Deductive reasoning is a logical process in which a conclusion is based on the concordance of multiple premises that are generally assumed to be true. This research has used the deductive reasoning method, where deductive reasoning proceeds from general premises to a specific conclusion in which researcher develops hypothesis and design a research strategy to test the formulated theory (Saunders et al., 2009). The study used descriptive research design through survey research approach.

\subsection{Population and Sample}

The population for the study includes 1100 managerial level employees, 100 middle level managers, and 15 corporate level managers working at the Company limited. A sample of 104 employees was randomly selected for interviews comprising of the all three levels of top, middle and lower levels of management. Stratified sampling method was applied to select the sample from the study population. In addition, 17 customers were randomly selected to measure their level of satisfaction of the services offered to illustrate the organizational performance.

\subsection{Measurement of Constructs}

Workforce quality is measured with the sub variables of commitments, qualifications, expertise, achievement orientation and accountability adopted from [10], [23], [21] and [5] which comprised total 10 factors. Management quality was measured by leadership and decision making by 8 factors and work Environment consist of 22 factors adopted from [7], [20], and [13]. Customer satisfaction, employee satisfaction, sales growth and profit growth were used to measure organizational performance. Customer satisfaction and employee satisfaction measures were adopted from [3], [24] and [6]. A five point likert scale was used to measure the workforce quality, management quality and organizational performance. Cronbach alpha represent $0.93,0.87$ and 0.91 for management quality, workforce quality and organizational performance respectively which represent good reliability of the constructs.

\subsection{Method of Data Collection and Analysis}

The primary data were collected through a selfadministered questionnaire and the respondents have the opportunity to answer at their convenience. By adopting this method, the researcher does not need to have early appointments to meet the respondents. This is also comparatively an economical method. Therefore, the researcher adopted this method to collect information from the respondents. The questionnaire was pre-tested with a sample of respondents to avoid misunderstandings and checked by three management experts to confirm the validity. The unit of analysis for the research was the individual employees at different levels and customers. The research study was carried out in a natural environment where organizational activities and processes take place. Apart from the questionnaire, face-to -face interviews were conducted with the customers to measure the satisfaction. Annual reports of the company were used as a secondary data. Descriptive statistics and inferential analysis were conducted to analyze data. Correlation analysis was applied to analyze relationship between independent and dependent variables and regression analysis was run to test the hypothesis.

Skewness and Kurtosis are used to measure the normality in the data set. Skewness of organizational performance is 0.547, proving that data are normally distributed. Multicollinearity of the independent variables were tested by using Variance Inflation Factor (VIF) which shows 1.53, 1.78 and 1.46 for workforce quality, management quality and organizational performance respectively, and verify that there is no multicollinearity among variable as the values are below 5.0.

\section{Findings}

\subsection{Profile of Respondents}

The total sample was consisted with 104 respondents and out of total sample, 40 respondents were top and middle management with the percentage of 33. Sixty four respondents were front line management with the percentage of 53. Top management and middle management were consisted with 40 respondents with males' percentage of $96.2 \%$. Sample was subdivided in to three age categories such as age between $18-35,35-50$ and more than 50 years. Top and Middle management represented the age group of 18-35 with the percentage of $46.2 \%$. Second majority from this category was respondents between $35-50$ years with 14 respondents and they were representing $25 \%$ from this category. There were no respondents who represent the age group above 50 years.

\subsection{Descriptive Statistics}

Mean values and standard deviation is illustrated in Table 2. Among the two independent variables, workforce quality represents the highest mean value of 3.82, where management quality represents the mean value of 3.64. Workforce quality of the organization was measured with employee commitment, employee qualifications, employee expertise knowledge to perform in the given task, employee achievement orientation, and employee accountability. An employee qualification indicates the lowest mean value of 3.73 while employee expertise was recorded the highest mean of 3.93 values. Management quality of the organization was measured with two areas such as leadership \& decision making and work environment. Mean value of leadership and decision making is 3.78 which represent the highest value and the mean value of work environment is 3.50. Further, out of the measures of organizational performance, mean value of customer satisfaction and sales growth represent highest mean value of 4.00 . 
Table 2. Descriptive Statistics.

\begin{tabular}{lll}
\hline Workforce Quality & Mean Value & $\begin{array}{l}\text { Standard } \\
\text { Deviation }\end{array}$ \\
\hline Workforce Quality & 3.82 & 0.679 \\
Commitment & 3.78 & 0.862 \\
Qualification & 3.73 & 0.679 \\
Expertise & 3.93 & 0.616 \\
Achievement Orientation & 3.85 & 0.580 \\
Accountability & 3.80 & 0.657 \\
Management Quality & 3.64 & 0.872 \\
Leadership and Decision Making & 3.78 & 0.782 \\
Wok environment & 3.50 & 0.963 \\
Organizational Performance & 3.89 & 0.768 \\
Customer Satisfaction & 4.00 & 0.644 \\
Employee satisfaction & 3.59 & 0.782 \\
Sales growth & 4.00 & 0.693 \\
Profit growth & 3.94 & 0.954 \\
\hline
\end{tabular}

Source: Survey Data, 2016

\subsection{Hypothesis Testing}

Hypothesis 1 indicated that there is a positive relationship between workforce quality and organizational performance. The model fit of the study is analyzed by taking into account the adjusted R Square value. According to Table 3 the $B$ value of the relationship between workforce quality and organizational performance is 0.578 , where adjusted $\mathrm{R}^{2}$ is 0.653 at coefficient value of $99.9 \%$ significance level. The Adjusted $\mathrm{R}^{2}$ value indicates the impact of independent variable on dependent variable compared to other factors. In this study the Adjusted $\mathrm{R}^{2}$ implies that 65.3 percent of the total variance of organizational performance is explained by workforce quality. Therefore, hypothesis 1 is accepted

Hypothesis 2 specified that there is a positive relationship between management quality and organizational performance. Adjusted $\mathrm{R}^{2}$ value of 0.653 indicates that 65.3 percent of the total variation in organizational performance is elucidated by management quality. Thus, hypothesis 2 also accepted. Findings imply that management quality and workforce quality are important factors to achieve high organizational performance.

Table 3. Model Summary.

\begin{tabular}{llllll}
\hline Variable & B & $\mathbf{R}^{2}$ & Adjusted $\mathbf{R}^{2}$ & T & Significance \\
\hline Workforce quality & $* * .578$ & .720 & .653 & 3.662 & .000 \\
Management quality & $* * .578$ & .650 & .653 & 4.662 & .000 \\
\hline
\end{tabular}

Predictors: (Constant), workforce quality, management quality,

Dependent Variable: organizational performance

** Significant at the 0.001 level

Source: Survey Data, 2016

\section{Discussion and Conclusion}

The present study investigated the relationship between workforce quality and management quality with organizational performance at one of the leading engineering company in Sri Lanka. Findings of this study is harmonious with some previous studies; [1] measured managers' perceptions of their effectiveness in administering twenty selected management practices and then looked at the correlation between the most effective management practice and organizational productivity, with performance management practices yielding the most significant relationship. However, several same researches have struggled to provide evidence on these relations. According to opinion given by the respondents, the employee commitment that builds the quality of the organization's workforce through attention to attracting, selecting, and developing staff for their career development. Empowerment of the officers are needed through decentralized decision making, accept creative ideas suggest by employees, reduce status distinctions, and motivate team working.

In accordance with achievement orientation, respondents are only moderately satisfied with opportunities available to fully utilize their skills. To satisfy this need in full, the company should first need to have a program to identify the skills of managers, improve and give opportunities to managers and officers to utilize those skills for maximum. At the same time there should be a clear policy to recognize and reward the achievements of the employees.

In hygiene factors, under supervision, respondents are more satisfied level of supervision and the constructive feed backs given. However, this situation could be further improved if periodical informal interviews could be arranged with superiors. When comes to remuneration, respondents are satisfied to certain satisfactory level with their pay. However, the company needs to introduce performance based incentive schemes to managers.

When it comes to working environment respondents are of the opinion that team concept needs to be given more importance and overall working environment needs improvement. Respondents are quite happy about the company policies and they think the company is well responsive to changes in the environment and they are also satisfied with emphasis on ethical behavior. However this could be further strengthen by continues updating of changes taken place in the work environment developing systems to track changes such as management information systems and intelligence systems.

Respondents are of the opinion that there are some concerns with respect to collective decision making. This may be due to lack of correlation among the managers. To overcome these situation periodical manager meetings needs to be scheduled. Respondents are not satisfied with the time available for them to be with their families. This is a very serious social issue and could be one of the top reasons of demotivating managers. This could be a common scenario for 
the construction industry. However, this should be immediately rectified.

\section{Recommendations}

The following specific recommendations are suggested to be implemented to improve the working conditions.

i. It is recommended that the pay and promotion policies and procedures be checked to ensure that they are equitable.

ii. Performance based incentive system or managing for development results concepts should be incorporate in the master plan to motivate employees.

iii. The organization structure should be revised with more horizontal level categories with more individual level responsibility.

iv. The revision of service minute is essential in order to provide more opportunities for career advancement. It should indicate a new advance career pathway towards organizational as well as individual level success.

v. Recognition plays an important role in job satisfaction. Therefore leadership qualities should be developed rather than the managerial skills among the bureaucrats in the top levels of the organization to provide more recognition to the employees as well as the service.

vi. Succession planning is also important with a long term focus.

vii. Whilst the research has shown the employees are satisfied overall, it is recommended that management at the company and they should maintain this level of satisfaction or increase it to a higher level. This is necessary since an organization that has satisfied employees performs better. In order to accomplish this, it is recommended that such surveys be administered periodically and remedial action be taken where necessary.

\section{Limitation and Future Research Direction}

One of the main limitations of this study is that this study has investigated the relationship between management quality and workforce quality with organizational performance by selecting only one firm operating in the engineering field. Future research can focus to investigate the same study including several organizations operating in different industries and cultural setting comparatively with a large sample.

\section{References}

[1] Abernathy, W. B. (2011). An analysis of the effects of selected management practices on organizational productivity and performance, Performance Improvement, Vol. 50 No. 6, pp. 39-47.

[2] Battisti, G. and Lona, A. (2009). The UK productivity gap in the service sector: do management practices matter? International Journal of Productivity and Performance Management, 58(8), pp. 727-747.

[3] Benham, (1993). The Right to be Human: A Biography of Abraham Maslow. Los Angeles.

[4] Bloom, Nicholas, Carol Propper, Stephan Seiler and John Van Reenen (2013). The Impact of Competition on Management Quality: Evidence from Public Hospitals. CEP Discussion Paper No. 983.

[5] Bradley, M., Petrescu, B. and Simmons, A. (2004). A qualityof-life theory derived from Maslow's developmental perspective: 'quality' is related to progressive satisfaction of a hierarchy of needs, lower order and higher. American Tarcher. Journal of Economics and Sociology, 45(3).

[6] Brenner, Vincent, C., Carmack, Claude, W., Weinsteein, and Mark, G. (2015). An Empirical Test of the Motivation-Hygiene Theory. Journal of Accounting Research, 9, pp. 2:359-366.

[7] Chalhoub, M. S. (2009), the effect of management practices on corporate performance: an empirical study of nongovernmental organizations in the Middle East, International Journal of Management, 26, 1: pp. 51-76.

[8] Connor, Patrick E. (1997). Total Quality Management: A Selective Commentary on Its Human Dimensions, with Special Reference to its Downside. Public Administration Review, Vol 57:6. pp 501-509.

[9] De Waal. (2017). Evaluating High Performance the EvidenceBased Way: The Case of the Swagelok Transformers. Sage Publications, pp. 1-15.

[10] De Waal, Béatrice I. J. M, and van der Heijden. (2015a). The Role of Performance Management in Creating And Maintaining a High performance Organization. Journal of Organization Design, Vol. 4 No. 1. pp. 1-11.

[11] De Waal, A., Mooijman, E. and Ferment, M. (2015b). From crisis to all-time high performance: using the HPO framework to improve customer relations at Ziggo, Global Business \& Organizational Excellence, Vol. 34 No. 2, pp. 6-18.

[12] Glasser, W. (1993). The quality school teacher. New York: Harper-Collins.

[13] Hertzberg, F. (1968). One more time: How do you motivate people? Harvard Business Review.

[14] Juran, and Gayan, F. (1993). Quality Planning and Analysis. 3rd ed. New York: McGraw-Hill Book Company.

[15] Keller, G,( 2011). Comparing the Effects of Management Practices on Organizational Performance between For-Profit and Not-For-Profit Corporations in Southeast Wisconsin. Journal of Business \& Economics, vol. 9, no. 3, pp. 29-37.

[16] Lam, Simon S. K. (1997). Influencing Tactics on Successful Implementation of Quality Improvement Policies. Psychological Reports, Vol 80, pp1 155-1 158.

[17] Maes, J., Sels, L. and Roodhooft, F. (2005). Modeling the link between management practices and financial performance. Evidence from small construction companies. Small Business Economics, 25 (1), pp. 17-34.

[18] Morrison, K. (2012). Searching for causality in the wrong places. International Journal of Social Research Methodology, Vol. 15 No. 1, pp. 15-30. 
[19] Parnell, J. A. Lester, D. L., Long, Z., Koseoglu, M. A. (2012). How environmental uncertainty affects the link between business strategy and performance in SMEs: Evidence from China, Turkey, and the USA. Management Decision, Vol. 50 No. 4, 2012, pp. 546-568.

[20] Porat, and Ben, (1977). Guttman Scale Test for Maslow Need Hierarchy. The Journal of Psychology, 97, pp. 85-92.

[21] Rowan, and Jhon, (1999). Ascent and Descent in Maslow Theory. Journal of Humanistic Psychology, 39, pp. 3:125-133.

[22] Saunders, M., Lewis, P. \& Thornhill, A. (2009). Research methods for business students, 5th ed., Harlow, Pearson Education.
[23] Shoura, M. and Singth, A. (1998). Motivation parameters for engineering managers using Maslow's theory. Journal of management in engineering, 15, pp. 5.

[24] Sila, I. (2007). Examining the Effects of Contextual Factors on TQM and Performance through the Lens of Organizational Theories: An Empirical Study. Journal of Operations Management, 25, pp. 83-109.

[25] Waldman, D. A., Sully de Luque, M. and Wang, D. (2012). What can we really learn about management practices across firms and countries? Academy of Management Perspectives, Vol. 26 No. 1, pp. 34-40. 